\title{
La imagen de las sirenas en dos pasajes de la obra de Clemente de Alejandría: un caso de hibridismo cultural ${ }^{1}$
}

\author{
Jesús Caos Huerta Rodríguez ${ }^{2}$
}

Recibido: 28 de Mayo de 2020 / Aceptado: 26 de Julio de 2020

Resumen. En la obra de Clemente de Alejandría existen ciertos motivos temáticos que reflejan situaciones de hibridismo cultural. El caso de las sirenas constituye un ejemplo de esa realidad híbrida. Por esta razón, se aborda el análisis de dos textos donde el alejandrino cita de manera explícita a estos seres mitológicos. El primero de ellos es un pasaje de la Septuaginta (Strom. VI 50.4), el segundo es un fragmento atribuido a Eurípides. En ambos textos Clemente introduce algunas modificaciones con la intención de adecuar el texto recibido al contexto cultural desde donde realiza la lectura. Este hecho es un indicio de un permanente diálogo desde el hibridismo cultural, pues termina realizando lecturas novedosas de sus fuentes como producto de las preocupaciones temáticas de su horizonte cultural.

Palabras clave: Hibridismo cultural, sirenas, judeohelenismo, Septuaginta, Eurípides.

\section{[en] The image of sirens in two passages of the work of Clement of Alexandria:} A case of cultural hybridism

\begin{abstract}
In the work of Clement of Alexandria there are certain motifs that reflect situations of cultural hybridism. The case of sirens is an example of this hybrid reality. For this reason, this paper addresses the analysis of two texts where the Alexandrian explicitly quotes these mythological beings. The first is a passage from the Septuagint (Strom. VI 50.4), the second is a fragment attributed to Euripides (Strom. IV 172.1-2). In both texts Clement introduces some modifications in order to adapt the received text to the cultural context in which it is read. This fact is an indication of permanent discussion from to cultural hybridism, since it results in innovative readings of its sources as a product of the thematic concerns within its cultural horizon.
\end{abstract}

Keywords: Cultural hybridism, Sirens, Hellenistic Judaism, Septuagint, Euripides.

Sumario. 1. Introducción. 2. Las sirenas como figura de hibridismo cultural. 3. Las sirenas como trasfondo de la herencia del judeohelenismo: el caso de la Septuaginta. 4. Las sirenas en la obra de Clemente de Alejandría. 4.1. Uso de la Septuaginta: un texto híbrido (Strom. VI 50.4). 4.2. Las sirenas aladas: una composición híbrida (Strom. IV 172.1-2). 5. Conclusión.

Cómo citar: Huerta Rodríguez, J. C. (2021), La imagen de las sirenas en dos pasajes de la obra de Clemente de Alejandría: Un caso de hibridismo cultural, en Cuadernos de Filología Clásica. Estudios griegos e indoeuropeos 31, 123-146.

\footnotetext{
1 Este trabajo se ha realizado en el marco del proyecto de investigación I+D del Ministerio de Economía y Competitividad (España) titulado "Edición y estudio de textos bíblicos y parabíblicos" (FFI2017-86726-P).

2 Universidad Pedagógica Nacional, subsede Ensenada (México)

jhuertar@edubc.mx
} 


\section{Introducción}

El hibridismo cultural es un concepto que comienza a cobrar relevancia para dar cuenta del carácter intercultural de las relaciones entre grupos humanos, pueblos y civilizaciones. A través de esta noción se pretende caracterizar el hecho de que no existen identidades culturales que se hayan preservado al margen de cualquier intercambio cultural. Por el contrario, la historia de la humanidad es testimonio de un intenso diálogo entre cosmovisiones y universos simbólicos mediante los cuales se han ido construyendo los sujetos en la interacción con la 'otredad'. En algunas ocasiones este proceso de hibridismo ha sido más evidente en determinados contextos culturales; en otras, ha operado de manera implícita. Sea de una u otra forma las identidades culturales de los sujetos y pueblos se han definido y constituido a partir del encuentro con el otro.

Aunque la noción de hibridismo cultural es de cuño reciente, ello no significa que la realidad a la que alude también lo sea. Más bien, dicho concepto aporta una categoría de análisis que permite enfocar la mirada intercultural sobre cualquier periodo de la historia humana. De esta manera, el estudio de la Antigüedad Clásica, aun cuando no exista el término como tal en los textos de la cultura clásica, no queda exento de un acercamiento de esta índole. Las prácticas culturales de antaño siguen un registro similar a las que se efectúan en la actualidad; es decir, prevalecen narrativas y discursos que se construyen desde el intercambio y la interacción con el otro ${ }^{3}$. Sin recurrir a este tipo de nomenclatura conceptual, los trabajos de Cumont y Momigli$\mathrm{ano}^{4}$ son un ejemplo ya de este acercamiento a la historia de la Antigüedad Clásica. La tarea que se busca emprender en este documento no difiere del camino que ya se ha comenzado a recorrer; por el contrario, se desea contribuir con casos específicos a la ampliación de esta mirada.

Dentro de este horizonte epistemológico la obra de Clemente de Alejandría adquiere una relevancia inusitada. Aunque este filósofo cristiano alejandrino en su obra expresa determinados prejuicios culturales de su época, también manifiesta un diálogo fructífero y cercano con la cultura helénica que pudiera caracterizarse como un enfoque encaminado hacia el hibridismo cultural. Lejos de mostrar un menosprecio a la cultura grecorromana, como lo hicieron algunos autores de su época (Stroumsa 2012: 30-31), Clemente adopta una postura de diálogo y encuentro entre la incipiente cultura cristiana y la dominante cultura helenizada de su época. Sin asumirse

\footnotetext{
Cada vez es más frecuente encontrar la categoría de 'hibridismo cultural' para referir a ciertos aspectos culturales en los estudios de la Antigüedad. Al respecto Brakke (2010) es un buen ejemplo de cómo el concepto de hibridismo empieza a tener cabida en los estudios del cristianismo primitivo, pues señala lo siguiente: "Three key themes characterize this new work on early Christian diversity: hybridity, rhetoric, and ethnicity" (pág. 11), Más adelante añade de manera contundente: “Within religious studies the term 'hybridity' functions something like the old 'syncretism.' It marks the mixing, combining, and grafting of disparate cultural elements. But, while syncretism tended to work as the opposite of purity and so seemed to have a negative value, hybridity highlights cultural inequality within an empire and the ways that dominant and subordinate cultures mutually interact and create new cultural forms that are never pure or completely distinct. Hybridity suggests a process that is both inevitable and creative, indeed the only process by which subcultures flourish and grow" (Brakke 2010: 12). De igual manera Rankin (2006), citando a Tanner (1997), señala que desde su propia conformación el cristianismo presupone un hibridismo cultural: "Christian identity is established from the outset through the use of 'borrowed materials'. Christianity is a 'hybrid formation through and through"' (Rankin 2006: 19). También se puede hallar eco de esta perspectiva en Rowley (2014: 128) y Karanasiou (2017: 331), entre otros.

4 De manera específica se puede aludir a trabajos de Cumont (1989) Astrología y religión en el mundo grecorromano y de Momigliano (1975) Alien Wisdom. The Limits of Hellenization. Cf. Burke 2013: 70.
} 
explícitamente como tal, el filósofo alejandrino fue un personaje híbrido que supo expresar la fe cristiana naciente en las categorías del pensamiento helénico. Las posibilidades de exploración de este tópico en la obra de Clemente son innumerables; no obstante, para este documento se ha seleccionado el caso de las sirenas como tema de análisis con la intención de demostrar el hibridismo cultural en el pensamiento del alejandrino.

\section{Las sirenas como figura de hibridismo cultural}

El relato más antiguo conservado acerca de estos seres mitológicos es el que se encuentra en el canto XII de la Odisea (Hosftetter 1990: 13). En el sentido estricto el pasaje abarca apenas 35 versos, lo cual no es consecuente con la trascendencia que ha tenido en el arte y literatura desde la Antigüedad (Doherty 1995: 81). Resulta aún más sorprendente la atención recibida al canto de estas criaturas, pues la única ocasión en que se hace alusión al mismo, queda registrado en tan solo ocho líneas de la Odisea (Doherty 1995: 81). No obstante, el poder seductor de su canto es tal que aún sigue atrapando la imaginación de quienes se acercan a este relato; o bien, dicho de otra manera "The evocative power of the passage, then, seems to stand in inverse proportion to its length" (Doherty 1995: 81).

El episodio, que da cuenta del encuentro de Odiseo y su tripulación con las sirenas, está enmarcado dentro de una narrativa peculiar de frontera (Hartog 1999). Dicho de otro modo, los relatos comprendidos en los cantos IX-XII tienen como característica fundamental el contacto con mundos no humanos (Choza \& Choza 1996: 63). Así pues, en algún sentido, las sirenas representan esos otros mundos con los cuales lo humano entra en contacto. A partir de esos espacios es desde donde lo propio adquiere sentido frente a lo ajeno; representa el ámbito de lo 'transhumano', entendido este como "todo aquello que se comporta y funciona de un modo distinto a como acostumbran hacerlos los hombres. Todo lo que está más allá de su modo de ser. Allende sus límites" (Choza \& Choza 1996: 63).

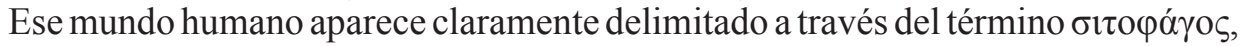
'que come pan's (Od. IX 191) $)^{6}$. Por mucho, queda atestiguado en la Odisea que el pan (harina) es el alimento neurálgico de la dieta humana (Od. II 290), pues este componente de la alimentación humana es mencionado más de 50 veces en la obra de Homero, lo cual constituye el nutrimento más aludido dentro del mundo homérico

5 Dicho término se emplea para distinguir al cíclope Polifemo de los humanos. La diferencia entre unos y otros

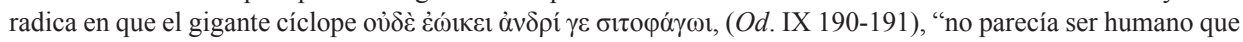
comía pan". El comer pan o no marca la frontera entre lo humano de aquello que no lo es, puesto que parte de

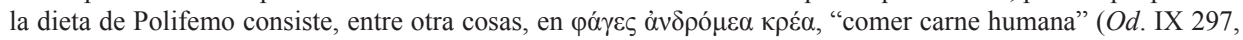
347).

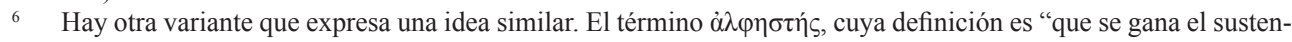
to, que trabaja para vivir o tal vez cuyo sustento básico es el cereal o concretamente la cebada" (DGE); aparece

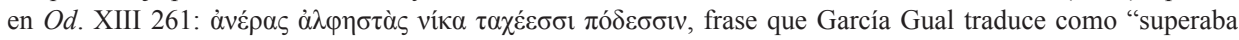
con sus rápidos pies a todos los hombres comedores de pan” ( $c f$. Od. I 349, VI 8). Sin embargo, García Gual no es consistente en traducir la expresión de la misma manera, pues la traduce de manera diferente en los tres casos referidos: comedores de pan, comedores de trigo, que son laboriosos. En contraste Tapia Zúñiga (2014) emplea la misma frase "hombres, que son industriosos" en las tres ocasiones. Una situación muy diferente es la traducción de Pabón (1982) que en ninguna de las tres ocasiones hace referencia explícita a idea de humanidad que sugiere la expresión. 
(Atienza 2007: 50-51). Por el contrario, hay un contraste notable respecto a la dieta de los dioses, de los seres no humanos y de las especies híbridas. Todos ellos no ingieren pan. En el caso de los dioses su dieta se compone de ambrosía y néctar? mientras que entre los otros no humanos se come loto o carne humana, según se trate de lotófagos, cíclopes o lestrigones (Bakker 2013: 26). En pocas palabras, participar del pan implica pertenecer al escenario humano; de ahí que, en las fronteras de lo no humano "el destino se juega a la mesa: olvido, animalización y muerte dependen del alimento que se ingiere (o que falta)" (Atienza 2007: 54).

A diferencia de la caracterización antropológica de Homero, las sirenas no pertenecen al mundo de lo humano, pues ellas no son comedoras de pan. Incluso el pasaje donde se les menciona, aun cuando no lo dice explícitamente, parece sugerir la idea de que se alimentan de sangre humana:

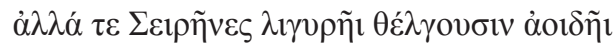

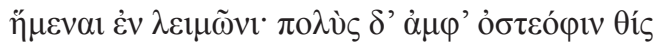

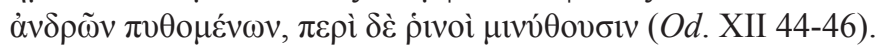

mas las Sirenas, con su altisonante canto lo encantan,

en un prado sentadas; y un gran montón de huesos en torno

hay, de hombres podridos, y en torno las pieles se encogen (Tapia Zúñiga).

Por otra parte, a pesar de que no se les describe físicamente, se puede inferir que son dos debido al uso del dual para referirlas (Hosftetter 1990: 13) ${ }^{9}$. Otro dato que también se infiere del texto es que son entes femeninos debido al género gramatical con el cual se les menciona (Hosftetter 1990: 13; Doherty 1995: 83). No obstante, esta información que proporciona el texto no es suficiente, pues existe omisión en los pormenores. De acuerdo con Heubeck (1990), ante la insuficiencia de datos, en los dos pasajes ${ }^{10}$ donde se hace mención a las sirenas, existen varias situaciones a las cuales se les brindan diferentes explicaciones debido a la carencia de detalles del relato homérico. En principio, la brevedad de ambas narraciones en la cantidad de datos está acotada solamente a la intención del texto; es decir, la idea consiste en la manera de evitarlas y no en las referencias acerca de su origen, aspecto físico, naturaleza de su canto o destino posterior a su enfrentamiento con Odiseo. Por esta razón, se recurre de manera constante a las representaciones disponibles en la cultura griega

$7 \quad$ Ejemplo de ello lo constituye el episodio donde se relata el encuentro entre Calipso y Hermes: "Tras haber hablado así, la diosa dispuso una mesa que colmó de ambrosía y mezcló el rojo néctar. Entonces tomó bebida y alimento el mensajero Argifonte" (Od. V 92-94, García Gual).

8 Así lo estima Rahner, quien interpreta este pasaje como un indicio de antiguas concepciones en las cuales las sirenas eran 'bebedoras' de sangre: "La etimología de la palabra griega seirenes significa las 'fascinadoras', las 'cautivadoras'. En su origen (que probablemente era anterior a los griegos) eran fantasmas de tipo vampírico que se alimentaban de la sangre de los cadáveres" (Rahner 2003: 327). Sin embargo, esas mismas líneas de la Odisea también pueden ser leídas en un sentido opuesto; así por ejemplo hay quienes hacen una lectura distinta: "La descripción homérica de los cuerpos marchitos pudriéndose en la playa parece excluir que las Sirenas los devorasen y sugiere, en efecto, una muerte por extenuación” (Jiménez San Cristóbal 2012: 130).

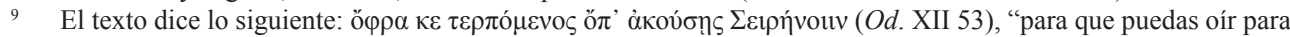
tu placer la voz de las sirenas" (García Gual). De igual manera se repite el uso del dual para referirse a las dos sirenas en XII 167; en este caso la diferencia con el genitivo plural de XII 158 obedece a cuestiones métricas (Heubeck 1990: 127).

10 Los dos pasajes referidos son XII 39-55 y 167-200. En el primer relato es la diosa Circe quien previene a Odiseo sobre el encuentro con las Sirenas. En el segundo, se narra el encuentro en sí. 
para intentar dar respuesta a algunas de estas interrogantes (Doherty 1995: 82). De este asunto se deriva una segunda situación problemática, la reconciliación del relato de la Odisea con las imágenes procedentes de las representaciones visuales del arte griego (Heubeck, 1990: 118).

Las representaciones proporcionadas por la Antigüedad sobre estos entes legendarios no se centran únicamente en el episodio de la Odisea; por el contrario, existe un repertorio de otros motivos artísticos relacionados también con estos ejemplares míticos que facilitan la comprensión de este ser cuyo canto resulta encantador (Heubeck 1990: 119). La imagen predominante surgida de las expresiones artísticas las sitúa como criaturas monstruosas que habitan fuera del ámbito de lo humano. Son seres que no atraen con su aspecto físico, pues su apariencia se asemeja más a pájaros alados ${ }^{11}$; más bien, su fascinación procede del canto y habilidad musical que poseen, así como del conocimiento o sabiduría que implícitamente pudieran ofrecer (García Gual 2014: 37-40).

El rasgo esencial de su representación física radica en su carácter híbrido. Las sirenas constituyen una síntesis de aspectos humanos con elementos animales (Doherty 1995: 82). Poseen un origen similar a las gorgonas, las esfinges, las arpías y las erinias y junto con todas ellas mantienen una asociación cercana al Hades, por lo cual están relacionadas con el espanto (García Gual 2014: 20). No obstante, su situación híbrida ante todo las ubica como "un ser entre dos mundos -la tierra y el mar, la vida y la muerte, este mundo y el otro, el mundo celeste y el submarino" (García Gual 2014: 12). Parte de la fascinación de los antiguos hacia esas figuras femeninas radica precisamente en dicha dualidad que les permite habitar dos mundos. Así las sirenas como elemento híbrido representan dos culturas, la humana y las transhumana. Una sola criatura puede encarnar dos horizontes culturales a la vez; en otras palabras, implica situar la vida en dos esferas existenciales distintas. De este modo, las sirenas son una construcción de frontera en donde no se asume una identidad unívoca, sino que se prestan para indicar el carácter poroso de las fronteras culturales.

\section{Las sirenas como trasfondo de la herencia del judeohelenismo: el caso de la Septuaginta}

Las sirenas como artefacto cultural del helenismo también dejan su huella en la mentalidad y escrituras hebreas. La traducción de las escrituras hebreas al griego, realizada por la comunidad judía de Alejandría, fue el comienzo de un proceso de helenización del texto del AT. De esta manera, la Septuaginta es el medio a través del cual se introduce en la tradición judía la presencia de estos seres híbridos. Junto con las sirenas también aparecen diversos motivos de la cultura helénica en la versión griega de los libros sagrados del judaísmo. Como parte de ese influjo helenístico resulta posible encontrar reminiscencias homéricas y platónicas en Proverbios, y además el libro de $J o b$ mantiene relación con la mitología y fábula de la literatura clásica (Fernández Marcos 2000: 314-315). En los libros de los LXX que no cuentan con el original hebreo (Vorlage) la influencia griega es aún mayor; así por ejemplo el libro de Sabiduría contiene 335 palabras que no están relacionadas con el léxico

$11 \quad$ Al respecto se pueden observar las ilustraciones en cerámicas y estatuillas recopiladas por Hosftetter (1990) hacia el final de su libro Sirenen im Archaischen und Klassischen Griechnland. 
habitual de la Septuaginta, sino con el vocabulario correspondiente a la filosofía y retórica en la prosa del helenismo tardío (Fernández Marcos 2000: 315).

Por consiguiente, la versión de los LXX no solo fue una traducción lingüística, sino que en esencia también implicó una traducción cultural (Hall 2010: 398; Burke 2013: 105-109). Esta última situación se presenta cuando existen "formaciones de identidad que atraviesan y cruzan fronteras naturales, y que están compuestas de personas que han sido dispersadas para siempre, sacadas de su tierra natal" (Hall 2010: 398). Sin duda estas palabras expresan la condición de vida de una buena parte de los judíos en Alejandría; en este sentido, se convirtieron ellos mismos en lo que podría denominarse un pueblo híbrido (Burke 2013: 86), es decir, habitaban por lo menos dos mundos, hablaban dos lenguas culturales (Hall 2010: 398).

Según Burke existen tres procesos o tipos de hibridismo: de los artefactos, de las prácticas y de las personas (Burke 2013: 73). De esos acercamientos, el que resulta más relevante para explorar, conforme a la intención de este documento, es el de los artefactos, puesto que en dicha categoría se pueden situar los textos en general. Bajo esta clasificación se ubican tanto la versión de los LXX como la obra de Clemente, en la medida que ambos conjuntos literarios corresponden a productos culturales acuñados en el crisol de la diversidad. No obstante, el caso más evidente de hibridación lo constituye la Septuaginta en vista de que es un ejercicio de traducción lingüística y cultural. Específicamente, las traducciones, como la versión de los LXX, "son el caso más obvio de textos híbridos, ya que la búsqueda de lo que a menudo se denomina 'equivalencia' implica la introducción de ideas y palabras que resulten familiares a nuevos lectores, pero no necesariamente a los pertenecientes a la cultura de la lengua en la que originalmente fue escrito" (Burke 2013: 76-77).

Así pues, un ejemplo fehaciente de dicho proceso de hibridismo en la cultura del judaísmo helenístico lo constituye la incorporación del término sirenas en la traducción de los LXX. La versión griega del AT retoma en su traducción la legendaria figura mitológica de las sirenas como parte de su léxico. De acuerdo con Rahner (2003: 330) fueron precisamente los traductores alejandrinos los que adoptaron la imagen de las sirenas para traducir dos palabras que refieren a dos bestias misteriosas. El primero de estos vocablos es מינת, tannîm, cuyo significado esencial es chacal; en tanto, el segundo es la expresión תונב הנעי, benôt ya 'anâh, que podría traducirse como el femenino de la palabra avestruz. Los pasajes de los LXX donde se inserta el término sirena son los siguientes:

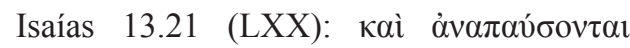

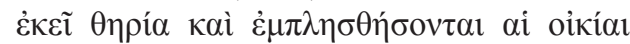

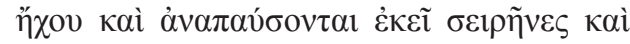

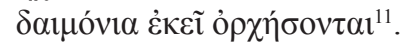

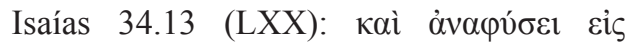

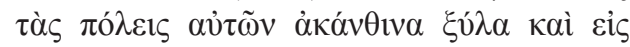

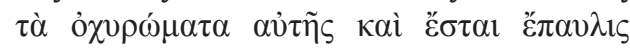

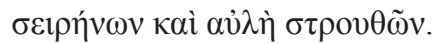

Allí descansarán las fieras y las casas se llenarán de ruido, y allí reposarán sirenas, y allí danzarán demonios.

$\mathrm{Y}$ en sus ciudades y en sus fortificaciones brotarán árboles espinosos y se convertirá en mansión de sirenas y habitáculo de gorriones-

12 El texto de la Septuaginta está tomado de la edición de Rahlfs-Hanhart (2006); en tanto, la traducción al castellano corresponde a las traducciones dirigidas por Fernández Marcos y Spottorno Díaz-Caro (2013, 2015). En las referencias siguientes a la Septuaginta se siguen utilizando las mismas fuentes señaladas aquí. 


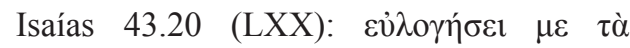

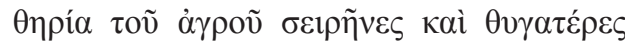

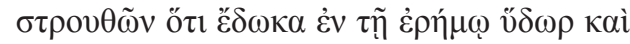

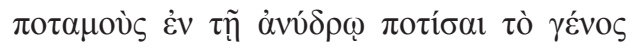

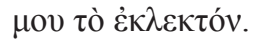

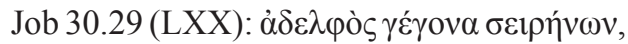
$\dot{\varepsilon} \tau \alpha \tilde{\rho} \rho \circ \varsigma \delta \grave{\varepsilon} \sigma \tau \rho o v \theta \tilde{\omega} v$.

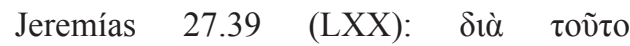

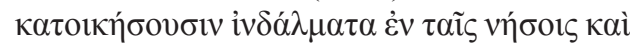

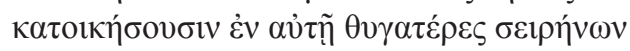

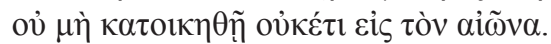

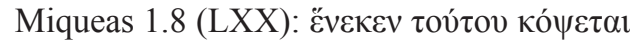

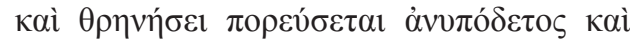

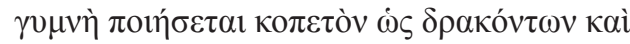

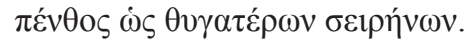

Los animales salvajes del campo me bendecirán, sirenas y avestruces, porque puse agua en el desierto y ríos en el páramo para abrevar a mi raza escogida.

En hermano de sirenas me he convertido, en compañero de avestruces.

Por eso habitarán apariciones en las islas y habitarán en ella hijas de sirena. Ya no será habitada más nunca.

Por eso se lamentará y gemirá, andará descalza y desnuda, prorrumpirá en lamentaciones como la de dragones y en duelo como el de hijas de sirena.

En los textos citados se puede apreciar que los traductores emplearon el término

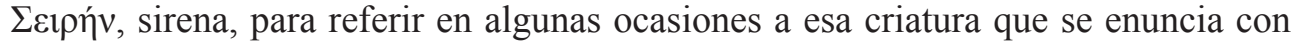
el vocablo hebreo tannîm. Sin embargo, no queda clara la razón de tal préstamo cultural, pues "sigue sin conocerse el porqué de esta traducción errónea pero sumamente interesante de los setenta traductores ${ }^{13}$ de formación helenística" (Rahner 2003: 330). Tal vez, una posibilidad de explicación sea que la palabra sirena aparece asociada con $\sigma \tau \rho o v \theta$ ós, 'avestruz, gorrión', (Is 34.13, 43.20; Jb 30.29). Además en el texto hebreo aparece el término tannîm asociado con el de avestruz הנעי תונבו מינת (Is 40.23) "los chacales y los avestruces" (Cantera - Iglesias). De ahí que posiblemente el traductor haya relacionado la frase הנעי תונב, benôt ya 'anâh ('hijas de avestruz') con las sirenas (Miq 1.8; Jr 27.39, cf. Jr 50. 39 TM), debido al parecido físico de los avestruces con las representaciones de las sirenas en la Antigüedad Clásica. En lugar de hablar de "chacales y avestruces", probablemente resultó más pertinente hacerlo de "sirenas y avestruces", pues ambos seres comparten cuerpo y extremidades inferiores en forma de ave.

Independientemente de cuál haya sido el origen de dicha traducción, lo cierto es que los judíos alejandrinos tenían a su disposición la imagen de las sirenas dentro de su propio texto sagrado. La inserción de las míticas sirenas en la Septuaginta también las convierte, de alguna manera, en una especie de artefacto cultural híbrido porque expresan la capacidad de habitar dos mundos, el griego y el judío. Son un constructo que procede de la cultura helénica, pero a la vez encuentran alojamiento dentro del horizonte cultural judío. El proceder de la diáspora judía en Alejandría permitió establecer un vínculo entre ambas culturas, pues fue capaz de evocar lo griego dentro de la tradición escritural hebrea, contribuyendo a la conformación de esa nueva realidad híbrida denominada judeohelenismo

No obstante, la comunidad judía de Alejandría no fue el único grupo religioso del judaísmo que adoptó la Septuaginta como texto fundante de su fe. Prontamente

13 El dato de los 'setenta traductores' corresponde a la Carta de Aristeas, donde de manera legendaria se describe este hecho. Sin embargo, la veracidad de dicha información es meramente "ficción literaria” (Fernández Marcos 2008: 23). 
también la versión de los LXX fue el canal a través del cual la naciente cristiandad recuperó el AT como parte de sus propias prácticas culturales. De hecho, como señala Fernández Marcos, "los cristianos leían la Biblia hebrea traducida al griego y ampliada con los deuterocanónicos, tal vez algunos pseudoepigráficos" (2008: 47). Por consiguiente, las comunidades cristianas inicialmente leyeron el texto griego y posteriormente fue la Biblia de los Padres de la Iglesia al menos hasta inicios del siglo III (Fernández Marcos 2000: 338). De esta manera, el cristianismo siguió las sendas del judaísmo helenizado y continuó en los dos primeros siglos adoptando y 'cristianizando' elementos y temáticas procedentes de la cultura clásica (Fernández Marcos 2000: 317, 2008: 48).

La Septuaginta, al ser parte constitutiva de la cultura religiosa del cristianismo en los primeros siglos, fue uno de los tantos medios que brindó la posibilidad de recuperar y reinterpretar determinados mitos y motivos clásicos en los Padres de la Iglesia. Así los cristianos, inmersos en un ambiente fuertemente helenizado, pudieron encontrar dentro de sus escritos sagrados, al igual que en su entorno cultural, el tema de las sirenas; y por más de un milenio las comunidades cristianas vinculadas a la cultura griega tuvieron acceso a estos textos (Rahner 2003: 330). Por ello no resulta extraño que cristianos pertenecientes a "dos mundos", como lo fue Clemente de Alejandría, hayan retomado el concepto de las sirenas en su obra. Ahora la tarea siguiente es indagar cómo y en qué contextos el filósofo cristiano alejandrino recupera esa imagen híbrida procedente de la cultura helenística y alojada también en la Septuaginta. La presencia de las cantoras en los escritos de los Padres de la Iglesia demuestra que "no existen fronteras culturales cerradas en sentido estricto, lo que hay es una especie de continuidad cultural" (Burke 2013: 64).

\section{Las sirenas en la obra de Clemente de Alejandría}

Los textos de la Septuaginta donde se alude a las sirenas no pasan desapercibidos en los textos de Clemente de Alejandría. Los préstamos culturales en los escritos del alejandrino demuestran que la globalización cultural, como el caso del helenismo en la Antigüedad, más que homogeneizar las prácticas culturales, en realidad las termina hibridando (Burke 2013: 64). El filósofo cristiano, al pertenecer a un entorno vinculado con la cristiandad griega, responde a ese proceso de intercambio cultural y termina recuperando en siete lugares de su obra la figura de las sirenas.

Al revisar los pasajes donde Clemente refiere de manera directa al tema de las sirenas es posible observar una diversidad de contextos a partir de los cuales evoca a estas criaturas híbridas. De las siete ocasiones en que alude a dichos seres mitológicos, solamente una vez cita de manera literal un pasaje de la Septuaginta (Strom. VI 50.4). En otra, recupera una cita directa de una supuesta tragedia de Eurípides (Strom. IV 172.1-2). En dos ocasiones más retoma la noción de las sirenas a partir de comentarios que realiza al texto de la Odisea (Prot. 118.1, Strom. VI 89.1). Por último, hay tres referencias más en las cuales ni cita texto alguno ni las vincula con el relato de Odiseo, simplemente da por sentado el tema de las sirenas como motivo cultural compartido con su audiencia (Strom. I 48.6; Strom. II 9.7; QDS 42.1).

De todas las referencias a las sirenas disponibles únicamente se analizan aquellas en las cuales hay una cita directa a un texto de por medio. La razón de tal recorte tiene como finalidad evidenciar el uso de los textos desde una perspectiva híbrida por 
parte de Clemente. En cierto modo, el tema de las sirenas en sí mismo representa ya un acercamiento de esta naturaleza; no obstante, la manera de interpretar los textos alusivos a ellas solo confirma la hibridez cultural subyacente en determinados aspectos del pensamiento del alejandrino. Por consiguiente, a continuación se procede solamente al análisis de las citas de Strom. VI 50.4 y Strom. IV 172.1-2, dejando para otra ocasión el análisis de las referencias restantes.

\subsection{Uso de la Septuaginta: un texto híbrido (Strom. VI 50.4)}

Como ya se había anticipado anteriormente, en la obra del alejandrino existe un solo pasaje perteneciente a la Septuaginta donde se alude de forma explícita a las sirenas. Clemente en Strom. VI 50.4 pretende citar el texto de Isaías 43.20. A continuación se presentan para su análisis ambos pasajes en paralelo:

Clemente de Alejandría ${ }^{13}$

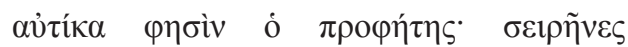

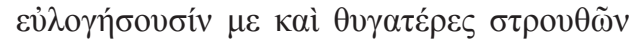

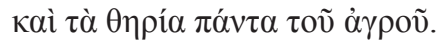

También dice el profeta: todas las fieras del campo, sirenas ${ }^{14}$ e hijas de avestruz me bendecirán.

\section{Septuaginta}

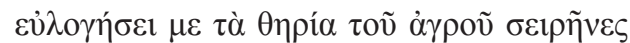

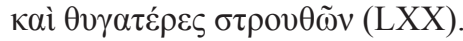

Las fieras del campo, sirenas e hijas de avestruz me bendecirá (sic).

Indudablemente Clemente pretende retomar un verso de la Septuaginta, pues introduce la referencia bíblica con una de las expresiones clásicas utilizadas cuando cita los escritos sagrados: comparar los dos textos se pueden apreciar notables diferencias entre ellos. A pesar de estar refiriéndose de manera explícita a un versículo del profeta Isaías, no lo cita de manera literal conforme al texto de los LXX disponible ${ }^{16}$.

En el texto griego se pueden percibir tres tipos de discrepancias: sintácticas, morfológicas y de léxico. En ninguno de los dos casos la sintaxis en el texto griego comienza con la frase que alude a las "fieras del campo". El pasaje de Clemente inicia con el término 'sirenas' seguido por el verbo 'bendecir' en tercera persona del plural; en tanto, la versión de los LXX inicia con el verbo 'bendecir' en tercera persona del singular, seguido del sujeto 'las fieras del campo'. El alejandrino termina con la construcción nominal "todas las fieras del campo"; mientras el texto septuagintal concluye con la frase "hijas de avestruz". Con referencia, al aspecto morfológico, el verbo principal es el mismo; coincide en el tiempo, mas no en el número. Por último,

14 Para el texto griego de Clemente se utiliza la edición de Stählin (1906).

15 Es de llamar la atención que la edición francesa Sources Chretiénnes no traduzca la palabra sirena como tal. En su lugar dice: "Des fauves me loueront, ainsi que de jeunes autruches et toutes les bêtes de la campagne" (Descourteeux 1999: 165). De igual manera Kelenhegyi (2017), aun cuando cita el texto griego, al momento de traducir el pasaje parece depender de la versión hebrea, pues traduce de la siguiente manera: "The wild animals will honor me, the jackals and the ostriches" (Kelenhegyi 2017: 224).

16 Bajo una traducción muy literal, transliterando el orden sintáctico del texto griego, podría leerse el texto de Clemente de la siguiente manera: "También dice el profeta: 'sirenas me bendecirán y las hijas de avestruz y las fieras todas del campo"”. En cambio el texto de la Septuaginta dice: "Me bendecirá las fieras del campo, sirenas y avestruces". 
en el texto clementino se introduce el adjetivo $\pi \alpha ́ v \tau \alpha$, 'todas', para caracterizar a las fieras del campo; en el caso de la Septuaginta se omite tal término.

A la luz de las observaciones anteriores se puede constatar que en esencia se utilizan los mismos términos, pero con un orden sintáctico distinto. Las diferencias expuestas se pueden explicar tal vez por el hecho de que Clemente está citando de memoria y no a libro abierto. Otra posibilidad quizá sea que el alejandrino esté corrigiendo de manera intencional el texto de la Septuaginta, ya que resulta evidente que la estructura morfológica del verbo 'bendecir' en los LXX es incorrecta, pues se utiliza el singular en lugar del plura ${ }^{17}$. Por consiguiente, Clemente está mejorando el texto al introducir la desinencia correcta del verbo.

En cualquiera de los escenarios anteriores o de algún otro hay una situación que merece ser resaltada con referencia a las prácticas culturales de la Antigüedad. Las técnicas de citación tienden a ser más flexibles y laxas en comparación con la actualidad (Huerta Rodríguez 2018: 61-66). La fijación del texto es más una característica de la mentalidad moderna; por el contrario, en el mundo antiguo, el texto permanece 'abierto' y puede ser susceptible de correcciones y de mejoras, o bien, de la introducción de ciertos elementos para aclarar una lectura ${ }^{18}$. Tal manera de relacionarse con el texto por parte de los antiguos permite la emergencia de textos híbridos; es decir, textos que incorporan nuevas lecturas con referencia al horizonte cultural desde el cual son leídos. De esta manera Clemente, como parte de la cultura helenizada a la que pertenece, puede introducir el aspecto gramatical adecuado del verbo. Además, hace un énfasis que la lectura original no contempla al insertar el término 'todas' para referir a las bestias del campo. La ampliación del texto en la dirección que sugiere el alejandrino le servirá para hacer más evidente su motivo teológico al momento de recuperar la referencia al profeta. Así pues, se está ante un texto híbrido que responde a las exigencias argumentativas de la exposición en curso. Sin duda, Clemente está citando el texto de Isaías, pero todo parece indicar que lo acomoda deliberadamente en sintonía con la secuencia lógica de la argumentación construida. Por tanto, es muy posible que el origen de la variación en la sintaxis, donde se enfatiza la palabra 'Sirenas' colocándola al inicio y el agregado del término $\pi \alpha ́ v \tau \alpha$, tenga su causa en una adecuación realizada intencionalmente.

Con la finalidad de apreciar el motivo teológico, el cual subyace detrás de las modificaciones de la referencia al profeta, conviene revisar el pasaje de Clemente en su contexto literario inmediato y remoto ${ }^{19}$. La cita de Isaías recuperada por Clemente forma parte de una temática consistente que se desarrolla dentro del sexto

17 Ya en la antigüedad es posible apreciar algunas correcciones a este verso del texto de la Septuaginta. Así, por

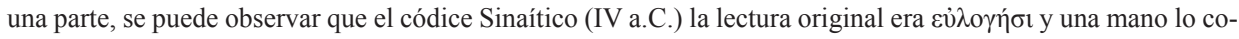

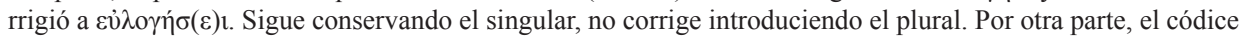

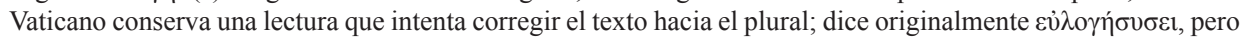
hay una corrección en la cual se lee $\varepsilon \hat{\lambda} \lambda \sigma \gamma \eta ́ \sigma(o) v \sigma \varepsilon 1$.

18 Un caso paradigmático que ilustra la manera en que los antiguos se relacionaban con el texto es la cita de Dt 18.15 entre los Padres de la Iglesia. El verso aparece dos veces en el libro de Hechos citado diferente en cada una de ellas. Clemente también la retoma una vez, pero aporta una versión distinta a las dos lecturas neotestamentarias. Ireneo, Tertuliano y Orígenes también hacen uso de ella y transmiten cada uno versiones distintas. En pocas palabras, la transmisión de la cita estuvo abierta durante los primeros cuatro siglos sin que el texto estuviera establecido de manera definitiva (Huerta Rodríguez 2018: 362-371).

19 Por 'contexto inmediato' se entiende el conjunto de ideas y versos que enmarcan la cita bíblica antes y después de su inserción. Se utiliza la expresión ‘contexto remoto’ para señalar el núcleo de ideas que construyen el discurso a lo largo del capítulo en general. 
capítulo del libro VI de los Stromata. El eje central de todo este apartado se centra en

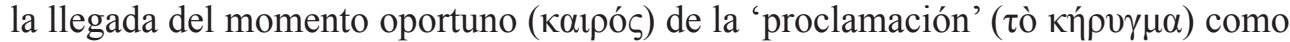
culminación de la salvación (Strom. VI 44.1-2). Para Clemente, tanto los bárbaros como los griegos fueron preparados para tal proclamación; los primeros con la Ley y los profetas, los segundos con la filosofía (Strom. VI 44.1). Sin embargo, esa preparación debería de ser complementada con la fe, de ahí que "a los justos según la Ley todavía les faltaba la fe [en el Señor]" y "a los justos según la filosofía no solo les faltaba la fe en el Señor, sino también el apartarse de la idolatría" (Clem.Al. Strom. VI 44.4; Merino 2005: 135, 137 ${ }^{20}$. Por esta razón, el Señor fue al Hades para evangelizar a los justos que residían en aquel lugar y no habían alcanzado la salvación mediante la fe (Strom. VI 44.5).

Desde la esencia de esa lógica desarrolla Clemente el argumento de todo el capítulo VI. Enfatiza el descenso de Jesús y de los apóstoles al Hades para proclamar el evangelio a los que murieron antes de la venida del Señor. Con la finalidad de apoyar tal argumento recurre a pasajes del Pastor de Hermas y de la Predicación de Pedro, los cuales utiliza como evidencia textual que confirman tal acontecimiento (Huerta Rodríguez 2018: 390-392). La razón que alienta todo este esfuerzo kerygmático se fundamenta en la siguiente premisa: "un justo en cuanto justo no difiere de otro justo, aunque pertenezca a la Ley o sea griego" (Clem.Al. Strom. VI 47.2; Merino 2005: 141). De ahí que, según Clemente, "sería un acto de clara iniquidad que los que han partido antes de la venida del Señor tuvieran salvación o castigo sin haber sido evangelizados" (Clem. Al. Strom. VI 48.4; Merino 2005: 143).

Es bajo este horizonte discursivo donde se inserta y adquiere sentido la referencia al texto de Isaías. La reunión de todos los justos conforma lo que se denomina ó $\lambda \alpha$ òs ő $\gamma 10 \varsigma$, ,el pueblo santo', el cual está constituido a su vez por el pueblo judío y el pueblo gentil arrepentido (Strom. VI 50.1). De acuerdo con Clemente, la reunión de ese pueblo santo ya estaba anticipada en la Escritura cuando el profeta Isaías menciona que el buey y la osa andarán juntos (Is 11.7). Según la interpretación alegórica realizada, el buey representa al pueblo judío, mientras que la osa simboliza al gentil21. Ambos grupos humanos, una vez santificados, componen el pueblo santo. Es aquí donde Clemente apela al texto de Isaías 43.20 para confirmar que los gentiles tam-

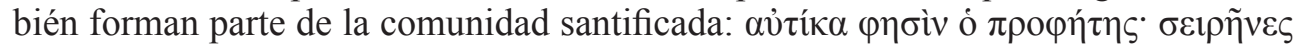

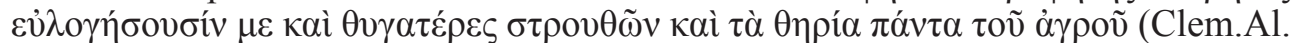
Strom. VI 50.4), "por esto dice el profeta: las sirenas me bendecirán, así como las hijas de avestruz y todas las fieras salvajes".

En primera instancia resulta intrigante cuál es la relación que establece entre la cita de Isaías 43.20 con la temática del pueblo santo, compuesto por judíos y gentiles. A simple vista no es tan evidente la conexión del tema de las sirenas, avestruces y fieras del campo con la idea de la proclamación, la evangelización en el Hades y la integración de un solo pueblo en la fe. La pista de interpretación viene un poco más adelante cuando Clemente define el significado de fieras salvajes o del campo. Hay tres elementos que integran el horizonte semántico que le lleva a retomar el pasaje

20 Al respecto Osborne (2005) expresa la misma idea: "Mankind is not divided by three different natures; rather, the lord has come in three different ways: the gospel was proclaimed at the appropriate time, just as the law and prophets had been earlier proclaimed and philosophy propounded to prepare human ears to receive the gospel" (Osborne 2005: 36).

21 La interpretación alegórica cristiana de los animales domésticos y salvajes para referirse respectivamente a los creyentes y ‘paganos' es un motivo recurrente en la exegesis de los Padres de la iglesia (Kelenhegyi 2017: 222). 
del profeta; así pues por fieras salvajes entiende el mundo, los animales impuros, los salvajes según la fe (Strom. VI 50.5). Indiscutiblemente con esta triple caracterización está aludiendo a los gentiles, a los 'paganos', a todos aquellos que previamente había referido por el término 'osa' en relación con el buey.

A la luz de las consideraciones anteriores resulta claro que el alejandrino emplea el texto de Isaías 43.20 para aludir a los gentiles. A esos mismos gentiles vuelve a hacer mención unas pocas líneas más adelante cuando se refiere a ellos como, $\tau$ ov̀ $\varsigma$

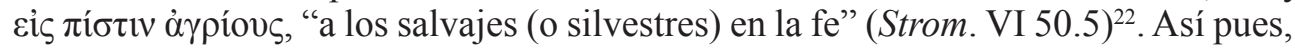

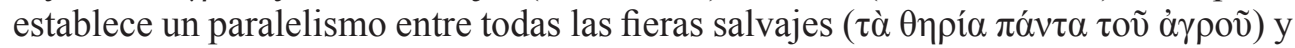

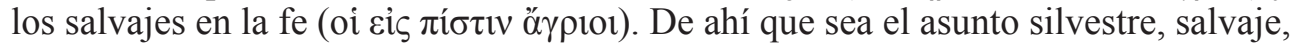
lo que le lleva insertar el texto isaiano dentro de su exposición. El vínculo que le permite echar mano del texto de la Septuaginta con la propuesta argumentativa que está desarrollando radica en el aspecto salvaje de la fe simbolizado en el caso de las fieras salvajes ejemplificadas en las sirenas.

Ahora bien, resulta evidente que el motivo de las sirenas y avestruces definitivamente está ligado a la concepción de fieras salvajes o del campo, pues el filósofo alejandrino a través del termino óypıs, 'salvaje, silvestre', define a los carentes o faltos de fe para la salvación. Clemente desde el principio de esta sección había convenido en que había dos clases o tipos de justos a los que les faltaba la fe; es

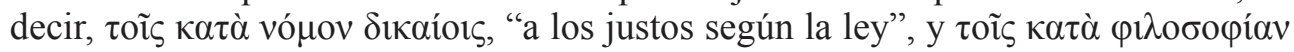

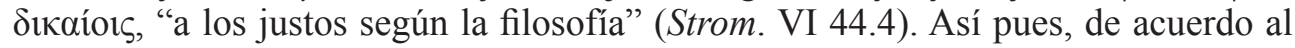
alejandrino, hay dos vías de justicia incompletas que carecen de fe. Cada una de esas vías de justificación corresponde a dos tipos de gentiles: a los bárbaros les es propia la Ley y a los griegos les concierne la filosofía (Strom. VI 44.1). De esta manera, en la perspectiva de Clemente, ambos grupos, sean bárbaros-Ley o griegos-filosofía, se encuentran en la misma situación, pues los dos son parte de esas fieras salvajes que poseen una fe también salvaje. Tal vez por esta razón, se presenta la adecuación al texto de la Septuaginta al agregar 'todas' para enfatizar la totalidad de los gentiles; independientemente de su relación con la Ley o la filosofía, sean bárbaros o griegos, 'sirenas' o 'avestruces', todos tienen la oportunidad de integrarse al pueblo santo,

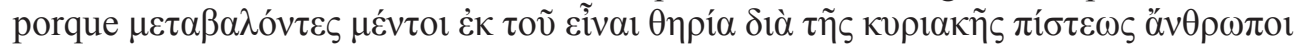

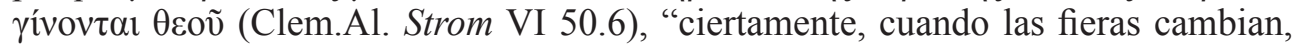
por su fe en el Señor, llegan a ser personas de Dios".

En este contexto interpretativo el texto recuperado de Isaías ofrece varias pautas para realizar una lectura desde la perspectiva del hibridismo cultural. En principio el recurso de las sirenas para aludir implícitamente a una parte de la humanidad gentil constituye una metáfora que da cuenta del carácter híbrido del pueblo santo. No existe un horizonte cultural único en la integración de esa nueva realidad humana emergida de la proclamación del evangelio, sino que la imagen evocada corresponde a la de un pueblo híbrido (Burke 2010:86). Con toda probabilidad tal vez esa sea la misma situación cultural de la audiencia del alejandrino; es decir, se está dirigiendo a una comunidad híbrida que pudiera verse representada en las sirenas y en las fieras salvajes. En otras palabras, la recuperación del texto isaiano estaría dejando entrever la composición cultural de la propia comunidad cristiana de Alejandría.

22 La idea de la carencia de fe como símbolo de naturaleza salvaje es evidente en este pasaje. Así también lo atestigua Kelenhegyi (2017: 223-224): "the wild nature of the Gentiles, on the other hand, expresses, their lack of faith". 
Aún más, la referencia a Isaías no solo pudiera dar cuenta de la comunidad cristiana en sí, sino también de la condición de vida de algunos creyentes en forma particular. Las sirenas como seres híbridos de la mitología griega ejemplifican una manera de habitar entre dos escenarios culturales distintos, pues hay que recordar que las representaciones disponibles de ellas muestran una criatura con un lado humano y otro salvaje, rostro de mujer con cuerpo de ave. Para el caso, de la comunidad se podría hablar de creyentes que habitan dos espacios culturales: el cristiano y el 'pagano'; es decir, poseen la Ley y la filosofía como elementos humanizadores, pero a la vez tiene una fe salvaje. Esta tal vez sea la razón por la cual Clemente modifica el texto de los LXX y coloca primeramente a las sirenas con la intención de enfatizar la situación híbrida de algunos cristianos alejandrinos. La idea implícita detrás de esta interpretación no es la renuncia a la Ley o filosofía, sino que se puede asumir una postura cristiana conservando los aspectos fundamentales de las prácticas culturales anteriores a la llegada de la fe. Dicho de otro modo, para Clemente la filosofía no resulta incompatible con el cristianismo, nada más se requiere adquirir fe. Por consiguiente, un creyente con este perfil es un ser híbrido, al igual que las sirenas, habita dos mundos culturales.

Por último hay un posible aspecto más que puede aducirse, aunque sea de manera breve, con referencia al empleo de la imagen de las sirenas en el contexto discursivo de este pasaje de los Stromata. En el mundo antiguo hay una asociación de las sirenas con el Hades debido al carácter híbrido con el cual se les describe como seres de frontera entre la vida y la muerte (García Gual 2014: 12-13; Jiménez San Cristóbal 2012: 142-147). A lo largo de todo este episodio, el tema del Hades es central en el discurso de Clemente. Tal vez, alguna conexión pudiera establecerse entre las sirenas, el Hades y la cita de Isaías. La mediación entre la vida y la muerte pudiera tener algún paralelo con el texto de Strom. V 48.7, donde se hacer referencia a escoger entre la muerte y la vida a partir de la cita de Dt $30.15,19$. En este caso las sirenas como criaturas hibridas serían la mediadoras de este proclamación que culmina en vida para quien responde en fe y en muerte para aquellos que no escuchan. Sin embargo, esta posible interpretación tiene la dificultad que la imagen de las sirenas se relaciona más como artefacto cultural funerario que acompaña al difunto durante su travesía hacia el Hades, pero no se señala el acompañamiento contrario, es decir, la conducción hacia la vida. Además, la inserción del pasaje del Deuteronomio aparentemente tiene una finalidad distinta que no se vincula en principio con la idea de las sirenas, sino con el descenso (katábasis) al Hades (Huerta Rodríguez 2018: 390-392).

\subsection{Las sirenas aladas: una composición híbrida (Strom. IV 172.1-2)}

Nuevamente las sirenas vuelven a aparecer, ahora hacia el final del IV libro de los Stromata. En esta ocasión Clemente refiere explícitamente a un texto de Eurípides, en el cual se habla de llevar puestas las sandalias aladas o encantadoras de las sirenas. Aunque el alejandrino atribuye la fuente a Eurípides cada vez más resulta común aceptar que el texto pertenece a Arquelao $^{23}$ o bien a Antiope ${ }^{24}$. En cualquier

\footnotetext{
23 Esta postura data desde inicios del siglo XX y actualmente la sostiene Karanasiou (2016: 339).

24 Este planteamiento también se sitúa desde antes de la primera mitad del siglo XX y es el que ha tenido más apoyo entre los estudiosos sobre el tema (Campos, González, López \& Romero 2007: 288-289; Martínez Bermejo 2017: 356).
} 
caso, lo cierto que estos versos citados por Clemente pueden ser ya encontrados desde el siglo III a.C. en la obra Vida de Eurípides del biógrafo peripatético Sátiro de Calatis. Por consiguiente, se dispone de dos versiones del mismo fragmento. A continuación se presenta ambos textos en paralelo:

\section{Clemente de Alejandría}

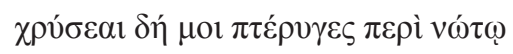

$\varphi \eta \sigma i$

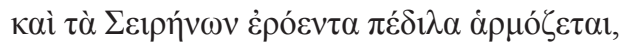

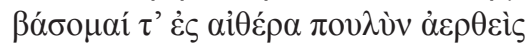

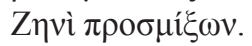

Alas doradas tengo en la espalda, dice, y llevo calzadas las encantadoras sandalias de las sirenas, subiré alzándome hacia el inmenso éter para unirme con Zeus.
Sátiro de Calatis

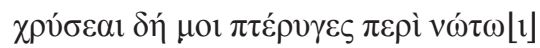

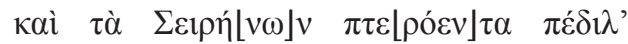

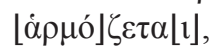

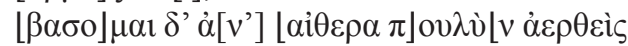

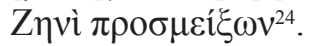

Alas doradas tengo en la espalda, y llevo calzadas las aladas sandalias de las sirenas, subiré alzándome al inmenso éter para unirme con Zeus.

Al comparar ambos textos emergen algunas diferencias. Clemente inserta de manera intercalada el verbo 'técnico' ( $\varphi$ $\sigma i ̀)$ con el cual introduce generalmente las citas de sus fuentes. Al proceder de esa forma interrumpe la secuencia de los versos 'euripidianos', pues no inserta el texto tal cual, sino que lo modifica ligeramente a su propio estilo de citación. Una segunda variante se encuentra en la lectura transmitida

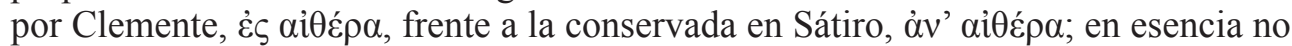
altera el significado del texto y no se puede establecer una modificación deliberada del texto (Martínez Bermejo 2017: 356). Una tercera variante puede ser localizada en el último verbo $(\pi \rho \circ \sigma \mu \mathfrak{i} \xi \omega v)$, aquí hay una diferencia menor respecto a la 'omisión' de una vocal, pero realmente el caso no es significativo porque no interfiere con el significado de la palabra.

Sin embargo, la diferencia más relevante de todas está relacionada con la va-

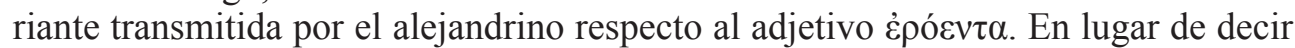
$\pi \tau \varepsilon \rho o ́ \varepsilon v \tau \alpha$, el texto del autor cristiano suprime las dos primeras letras para decir

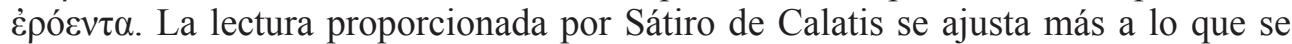
pudiera esperar a partir del contexto de la cita, pues anteriormente se mencionaban las alas en las espaldas, por lo cual resulta congruente que también las sandalias posean las mismas características con la finalidad de contribuir al ascenso a través del inmenso éter.

Sin embargo, no queda clara la razón del origen de la variante en el texto de Clemente, es decir, por qué leyó 'encantadoras' en lugar de 'aladas'. Una posibilidad acerca de esta modificación pudiera ser que Clemente lo está adecuando al 'uso cristiano de su época'; es decir, lo está 'cristianizando'. Es bien sabido que para el momento en el cual el alejandrino escribe, las sirenas se han convertido en sinónimo de voluptuosidad en la cultura cristiana (Rahner 2003: 336). Tal vez esa sea la causa por la cual el alejandrino decide introducir una modificación al texto para hacerlo coincidir con el entorno cultural del cristianismo del momento. Lo anterior

25 El texto griego está tomado de Martínez Bermejo 2017: 355-356. 
puede sustentarse en el tratamiento realizado ya en otros textos, donde existen modificaciones procedentes de un acercamiento híbrido a la cultura helenística ${ }^{26}$. Por consiguiente, es posible que aquí estuviera utilizando un procedimiento similar de hibridación al estar citando el texto del poeta trágico. De ser factible dicha tesis, entonces la referencia de Eurípides es en sí misma un elemento más que da cuenta del hibridismo cultural en el pensamiento de Clemente, el cual se ve reflejado en el tema de las sirenas y será motivo de discusión posterior.

La presentación del texto del poeta griego no es el único elemento híbrido en el tratamiento del tema de las sirenas a través de este pasaje, sino que la interpretación también contiene características de una lectura híbrida. Hay varios indicios de este acercamiento en diferentes autores que se han dado a la tarea de interpretar la cita de Eurípides dentro del pasaje de los Stromata. De acuerdo con Rahner (2003: 327), las sirenas encierran una dialéctica mítica, pues a la vez son seres celestiales e infernales. Esa perspectiva híbrida, debido a su doble naturaleza, ha sido un elemento central en la interpretación de tales seres, pues "a lo largo del tiempo, el embeleso de las Sirenas ha inducido a exégesis diversas que van desde equipararlas con prostitutas a la imagen de mujeres doctas, representantes de la sed humana de conocimiento" (Jiménez San Cristóbal 2012: 116). Parte de esa misma visión dual se encuentra dentro de los Padres de la Iglesia, donde "las sirenas simbolizan el placer mortal y también el saber mortal" (Rahner 2003: 327).

Indudablemente Clemente de Alejandría también comparte esa visión dialéctica de la época, pues él habita dentro de ese mismo universo simbólico y cultural. Así, en este pasaje de la obra del alejandrino, la cita del texto de Eurípides refleja un horizonte simbólico caracterizado por la concepción 'celestial' de las sirenas. Es un hecho que el mito de Er, conservado en la obra platónica, contribuyó a construir esa imagen de las sirenas como seres celestiales (Rahner 2003: 328; Rowley 2014: 330; Jiménez San Cristóbal 2012: 144-149) ${ }^{27}$. De esta manera, la representación predominante de las sirenas en este pasaje está relacionada con la función de ser mediadoras entre dos mundos con la capacidad de conducir a las almas en su viaje al más allá. Así, de acuerdo con Rowley (2014: 303), al interpretar este pasaje señala que "Clement himself is referencing a similarly positive, heavenly, image of the Sirens, when

26 Un ejemplo paradigmático es el tratamiento exegético realizado dos veces al texto de Gn 17.1-2 en Paed. I 56.2-3 (Huerta Rodríguez 2018: 126-134). Aquí se puede apreciar claramente cómo el alejandrino realiza adecuaciones al texto de los LXX para demostrar la coincidencia de la cita bíblica con su programa teológico; es decir, tiene la intención de presentar a Dios como pedagogo y la figura del patriarca como un 'niño' que es disciplinado por su instructor y para ello recurre a unas ligeras modificación del texto del Génesis. Este es sin duda un buen caso para mostrar que en ocasiones Clemente 'introduce el contexto cultural' en su citas 'textuales', con lo cual terminado creando una situación híbrida entre el texto y el mundo cultural desde donde interpreta la referencia.

27 Rahner (2003) señala al respecto que dicha imagen tuvo eco en la piedad de la Antigüedad tardía. Rowley (2014) sume también una postura similar y aporta como evidencia el célebre pasaje de Quaest.Conv., 744c746b, de Plutarco para mostrar que la interpretación platónica de las sirenas tuvo cabida en las discusiones de los antiguos. Además también hace mención de un pasaje en Filón de Alejandría (In Genesim 3.3) donde igualmente existe un influjo de las ideas platónicas sobre este tema y sugiere que probablemente también se encuentran detrás de los comentarios vertidos en De somniis 1.35 (Rowley 2014: 301). Aunque Jiménez San Cristóbal (2012) sugiere que esa visión de las sirenas tal vez ya se encuentra implícita desde el mismo pasaje homérico debido a que la narración se ubica justo después de su viaje al Hades y además la playa cubierta de cadáveres putrefactos y huesos evoca a las cantoras como intermediarias entre estos dos mundos (Cabrera 2012: 21 tiene una opinión similar). La misma autora también apunta que la imagen de las sirenas vinculadas al más allá está presente en Sófocles y Eurípides. Concretamente cita el conocido pasaje de Helena donde las sirenas son acompañantes del lamento fúnebre de la protagonista de la obra (Jiménez San Cristóbal 2012: 142-143). 
he preserves a fragment of Euripides" (cf. Karanasiou 2016: 340). Es una imagen que las termina convirtiendo en una especie de "ángeles acompañantes que facilitan al alma la subida a Dios" (Rahner 2003: 328).

Sin dejar de lado este núcleo principal de ideas latente en la incorporación del fragmento de Eurípides, como parte del ambiente cultural del alejandrino, también existen otros elementos que se encuentran presentes detrás de la inserción de dicha cita. Con referencia al contexto inmediato anterior, Karanasiou (2016: 340) destaca que "the theme of the context is the concept of 'ó $\mu$ oi $\omega \sigma l \varsigma \theta \varepsilon \tilde{\omega}$ ". De opinión similar es Martínez Bermejo (2017: 356), quien también sitúa el tema de la semejanza con Dios como el motivo central que da origen al uso de la cita de Eurípides. Definitivamente, este es un aspecto más a tener en cuenta al momento de realizar una interpretación acerca del sentido otorgado por Clemente al texto de Eurípides; en otras palabras, el contexto inmediato resulta fundamental para tener una comprensión adecuada de lo que pretende decir el alejandrino.

Una aproximación adicional, a las otras dos enumeradas, es aquella que pone énfasis en el contexto posterior a la cita. En este caso se destaca la cláusula con la cual inicia el comentario después de insertar el texto euripidiano, pues "is followed antithetically by غ̇ं $\dot{\omega} \delta \dot{\varepsilon}$, which is the opening line for Clement's allegorical analysis" (Karanasiou 2016: 340). Dentro de esta línea de interpretación, el alejandrino sustituye las alas doradas y las sandalias de Sirena por las alas que pudiera darle el Espíritu de Cristo y modifica el ascenso al Éter por Jerusalén como destino del viaje (Strom. IV 172.2; Karanasiou 2016: 341). Como parte de este contexto posterior a la cita también se resalta la redefinición realizada de la doctrina estoica de la 'ciudad' (Rowley 2014: 168-169; Karanasiou 2016: 341). No obstante, este debate parece alejarse ya de la temática de las sirenas, pues la discusión se centra en la ciudad celestial como elemento paradigmático de la terrenal.

Hasta el momento se ha hecho brevemente un recuento de la interpretación del fragmento de Eurípides en la obra de Clemente desde tres vertientes. En principio se le ha situado desde el horizonte simbólico de la época donde las sirenas adquieren un perfil de mediadoras entre dos mundos y se posicionan como acompañantes de las almas de los difuntos en su camino al Hades. Luego también se señaló el contexto inmediato anterior a la cita que la ubica dentro del tema de la 'semejanza con Dios'. Por último, se hizo mención al contexto inmediato posterior a la cita, en el cual Clemente redefine algunas características del texto al incorporar motivos cristianos en la relectura hecha. No obstante, queda pendiente por explorar un contexto más que no ha sido desarrollado cabalmente y que sin duda permite proyectar la exégesis empleada por el alejandrino dentro de las pautas del hibridismo cultural. Este elemento por considerar es la lectura desde el contexto remoto; es decir, el sentido que le confiere Clemente al texto dentro de todo el capítulo considerado este como una sola unidad narrativa. Esa es la tarea que se busca emprender en los siguientes párrafos.

El texto alusivo a las sirenas se encuentra al final del capítulo XXVI del libro IV de los Stromata ${ }^{28}$. Dentro del contexto general del capítulo la referencia a 'Eurípides' parece apelar a dos ejes fundamentales con referencia a la argumentación global. Por

28 Hay una alusión de esa situación en Karanasiou (2016: 340): “At the end of Clement's book the quotation from Euripides serves as a coda that supports his interpretation as a positive paradigm". Sin embargo el autor no desarrolla las implicaciones, sino solamente se concreta en insinuar brevemente el lugar que ocupa la cita dentro de la estructura general del capítulo. 
un lado, existe una vinculación directa con la discusión acerca de la importancia del cuerpo físico para el gnóstico. Por la otra, enfoca la cita con relación al ascenso hacia el cielo como la morada definitiva de aquel que ha alcanzado la semejanza divina. Estas dos orientaciones temáticas permiten situar el contexto remoto para interpretar la imagen de las sirenas que subyacen en el pasaje utilizado en la obra de Clemente.

Así pues, respecto a la primera temática, la función aparente de la cita consiste en ejemplificar la manera en la cual el cristiano gnóstico se desprende del cuerpo físico como última meta terrenal para finalmente allegarse a Dios. A lo largo de todo el capítulo el alejandrino ha venido discutiendo con aquellos que consideran la creación y, por consiguiente, el cuerpo, $\sigma \tilde{\omega} \mu \alpha$, como algo censurable (Strom. IV 163.1). La polémica en torno al cuerpo se manifiesta a través del uso de distintas expresiones y términos para referirse a él. Entre la nomenclatura empleada por parte de Clemente se encuentra

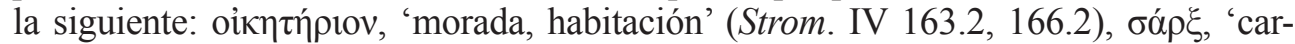

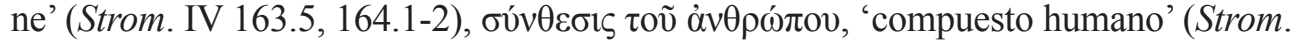
IV 164.5), бкп̃vos, 'tienda' (Strom. IV 165.2, 166.2), oikía, 'casa' (Strom. IV 166.2), $\pi \alpha \rho o u k i ́ \alpha$, 'residencia en país extranjero" ${ }^{29}$ (Strom. IV 166.1). Todos estos términos proporcionan un horizonte que permite interpretar el lugar que ocupa el fragmento de Eurípides en la estructura argumentativa del pasaje de Clemente. De acuerdo con el alejandrino hay quienes sin razón menosprecian el cuerpo y la carne (Strom. IV 163.1, 5) y, por tanto, se entregan a los placeres (Strom. IV 163.1) porque consideran que los elegidos pueden desatender el cuerpo sin preocuparse por el pecado. Clemente es contundente sobre este asunto y afirma que el cuerpo no es naturalmente malo (Strom. IV 164.3), por lo que resulta de vital importancia recuperar su valor para el creyente:

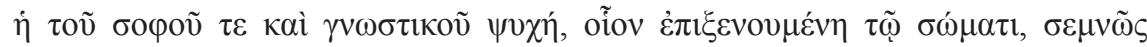

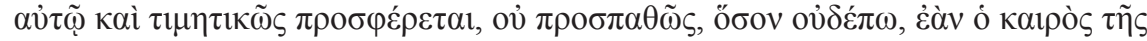

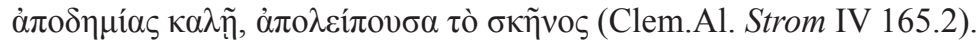

El alma del sabio y del gnóstico, cual huésped en el cuerpo, se comporta con él de forma digna y respetuosa, no con pasión; sin abandonar la tienda, por poco que sea, hasta que llame el momento de la partida (Merino).

La actitud del alejandrino contrasta rotundamente con aquella visión de quienes menosprecian la dimensión física de la creación. Hay un reconocimiento acerca del carácter provisional del cuerpo, pues el alma como extranjera en este mundo se hospeda temporalmente en él. Destaca en la cita el empleo del término ỏ $\pi \delta \delta \eta \mu i ́ \alpha$, 'salida, viaje' o 'viaje fuera de la patria ${ }^{30} \mathrm{La}$ idea que evoca esta palabra es la de alguien que viaja fuera de su lugar de estancia habitual; en otras palabras, sugiere que el hogar cotidiano del creyente es el cuerpo. Por consiguiente, la partida implica una vez más asumir la condición de extranjero, pues cuando el cristiano marcha de este mundo se encuentra fuera de la patria en busca de su nueva residencia.

La metáfora de la residencia transitoria del viajero es recurrente en todo este capítulo del libro de los IV de los Stromata. Según Clemente, así lo ejemplifica Abraham y el salmista (Strom. IV 165.3), los peripatéticos (Strom. IV 166.1), el apóstol Pablo (Strom. IV 166.3). Todos ellos entienden la morada temporal del alma en el cuerpo

29 "Sojourning in a foreign land" (LSJ 1996: 1342).

30 Así lo establece como principal entrada en Diccionario griego-español editado por el CSIC (DGE 1995: 411). 


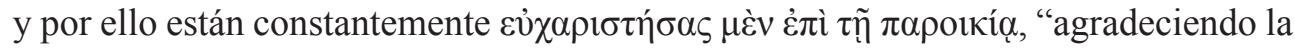
residencia en el país extranjero" (Strom. IV 166.1). Sin duda, parte de este escenario se encuentra implícito en la cita de Eurípides que utiliza Clemente. Las palabras del poeta griego están enmarcadas en este contexto de partida; es decir, refieren al viaje que el creyente emprende como parte de su $\alpha \dot{\pi} \delta \delta \eta \mu i ́ \alpha$ hacia la búsqueda de nuevo hogar a lado de Dios.

El segundo núcleo de ideas, para interpretar el texto de Eurípides en la obra del alejandrino, está relacionado con el lugar de la nueva residencia; es decir, el ascenso al cielo, o bien, la subida a través del inmenso éter. Al inicio del capítulo hay una afirmación de Clemente que puede tomarse como programática del discurso que va a desarrollar a lo largo de su exposición. Aquellos que menosprecian el cuerpo no son

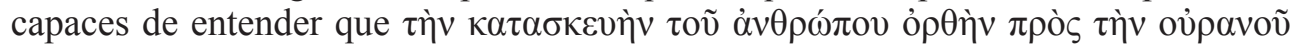

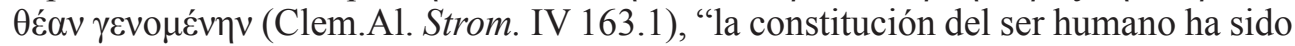
diseñada recta para la contemplación del cielo"31. Desde el inicio, juntamente con la revaloración del cuerpo, el alejandrino establece que la disposición natural de la humanidad está dirigida hacia el cielo.

A partir de esta segunda consideración toda una serie de referencias al cielo adquiere sentido dentro de la lógica de argumentación del alejandrino. En este contexto la introducción de la cita del apóstol Pablo cobra gran relevancia porque ilus-

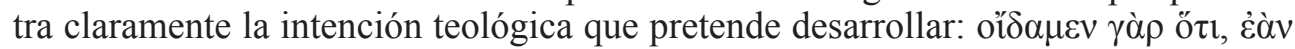

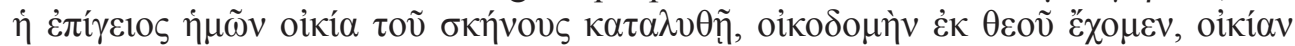

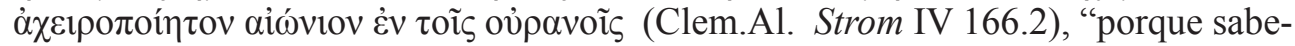
mos que si esta tienda, que es nuestra morada terrestre, se desmorona, tenemos un edificio que es de Dios: una morada eterna, no hecha por mano humana, que está en los cielos" (Cantera-Iglesias). Esta referencia aporta varios elementos a la estructura argumentativa empleada por Clemente. En principio, recupera la idea del cuerpo como recinto del 'alma'. También, le permite enfatizar el aspecto provisional de la morada. Implícitamente sostiene la noción de una peregrinación o de una existencia en calidad de extranjero, pues se establece de modo claro la existencia de dos habitaciones, una terrenal, otra celestial. Por último, enfatiza la morada celestial como el punto de arribo final tras la partida; es decir, el cielo es el lugar de residencia final.

La migración hacia el cielo como destino final del gnóstico cristiano no solamente está atestiguada por este texto neotestamentario. Clemente ofrece también evidencia escritural procedente de la tradición clásica. Al soporte bíblico empleado anteriormente le añade referencias de autores clásicos y con ello diseña una estructura argumentativa escritural híbrida, pues cita textos tanto de una como de otra fuente para construir un entramado de ideas con una misma orientación; en otras palabras, le interesa dejar claro que ambos referentes coinciden y componen una especie de hibridación cultural de la misma verdad. Así, de acuerdo con su núcleo de ideas, tanto Epicarmo ${ }^{32}$ como Píndaro $^{33}$ establecen el cielo como la morada final del piadoso

31 La idea de contemplar o mirar al cielo como parte constitutiva del ser humano está atestiguada en la figura de Abraham como astrólogo desarrollada por Clemente de Alejandría. El Patriarca escenifica el proceder del gnóstico que es capaz de alzar la vista y encontrar el conocimiento auténtico de las cosas (Huerta Rodriguez 2020).

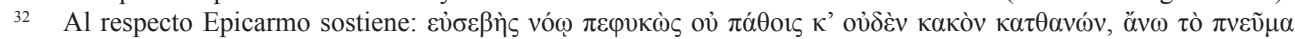

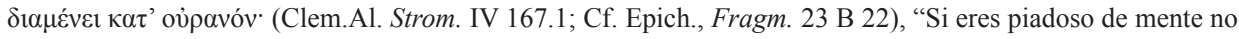
sufrirás ningún mal de la muerte, el espíritu permanece arriba en el cielo" (Merino).

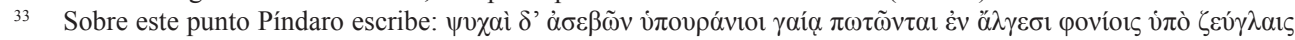

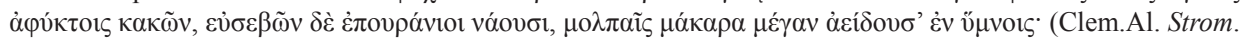




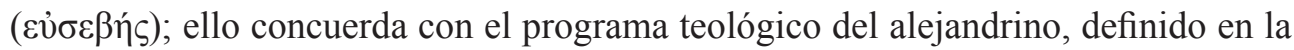

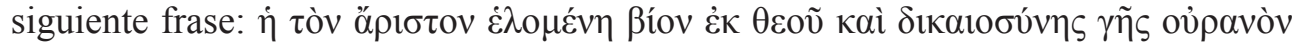
$\dot{\alpha} \nu \tau \alpha \lambda \lambda \alpha \alpha \sigma \sigma \varepsilon \tau \alpha 1$ (Clem.Al. Strom. IV 167.4), "el que escoge la mejor vida, la que procede de Dios y de la justicia, se ha cambiado de la tierra al cielo". Bajo dicha premisa, permanecer en la tierra implica situarse en el pecado; en cambio, aspirar al cielo es $\dot{\varepsilon} \xi o \mu o t o v ́ \mu \varepsilon v o \varsigma ~ \theta \varepsilon \tilde{\omega}$, "llegar a ser semejante a Dios" (Strom. IV 168.2). La interpretación que realiza de Isaías $1.2^{34}$ ratifica su argumento. Según él, cuando

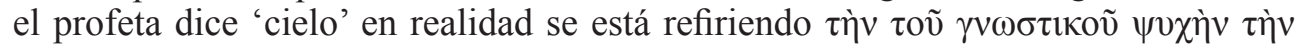

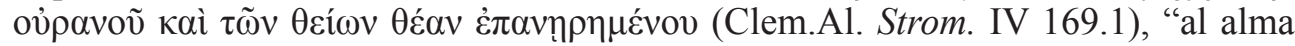
del gnóstico que ha entrado en la contemplación del cielo y de las cosas divinas".

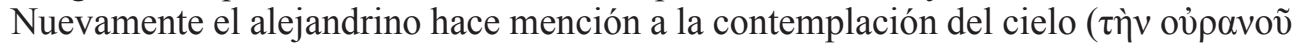
$\theta \varepsilon \dot{\alpha} \alpha)^{35}$ como una práctica esencial en la actividad humana, la cual conduce a la semejanza con Dios.

Clemente, de acuerdo con el razonamiento anterior, construye una 'cita bíblica' 36 para enfatizar el deber que tiene todo creyente o piadoso de imitar a Dios. Según

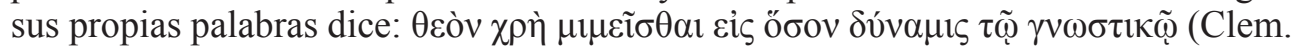
Al. Strom. IV 171.3), "es necesario cuanto pueda que el gnóstico imite a Dios". Así como la tradición clásica sostiene que el cielo es el punto de llegada para el piadoso, de igual manera sucede con la noción de la imitación o semejanza. Los autores clásicos también confirman esta misma idea. Para ello recurre, de manera parecida a como lo hizo con la 'cita bíblica', a la elaboración de una referencia 'híbrida' de la obra de Homero. Entresaca una serie de textos de diversos lugares ${ }^{37}$ y los une para construir una referencia a través de la cual pueda atestiguar que los poetas griegos asumen posturas similares a la que ha venido desarrollando:

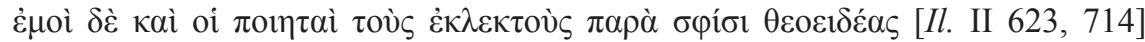

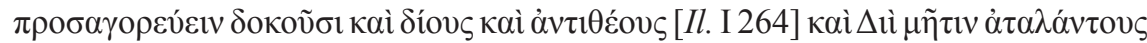

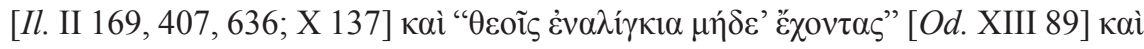

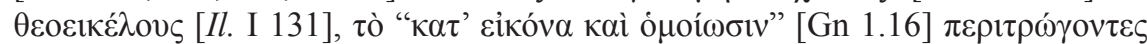
(Clem.Al. Strom. IV 171.4) ${ }^{38}$.

IV 167.3; Cf. Pi., Fragm. 132), "Las almas de los impíos revolotean sobre la tierra bajo el cielo en sangrientos dolores, bajo el yugo inevitable del mal; pero las [almas] de los piadosos viven en el cielo celebrando con himnos melodiosos al gran Bienaventurado" (Merino).

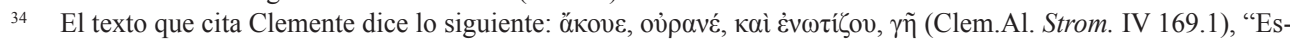
cucha, oh cielo, y presta oído, oh tierra".

35 Esta idea ya había aparecido al inicio del capítulo (Strom. IV 163.1) y ahora es nuevamente retomada aquí (Strom. IV 169.1)

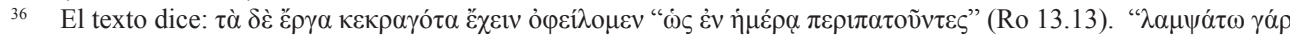

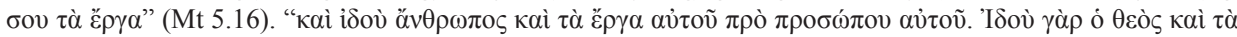

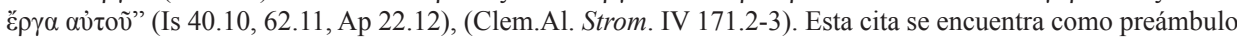
a la idea de que el gnóstico debe imitar a Dios en todo lo posible.

${ }^{37}{ }^{20}$ De acuerdo con el aparato crítico de la edición de Stählin (1906: 324), Clemente en Strom. IV 171.4 está citando o aludiendo a varios pasajes de la obra de Homero: Il. II 623,714; II 169, 407, 636, X 137; Od. XIII 89; Il. I 131. En la cita que viene a continuación se señalan los sitios donde se alude a Homero.

38 Los términos que emplea Clemente para definir los rasgos ilustres de los elegidos proceden de la obra de Ho-

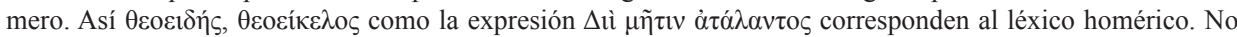
obstante, hay autores contemporáneos a Clemente que usan prácticamente el mismo vocabulario para hablar de

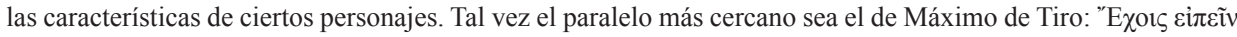

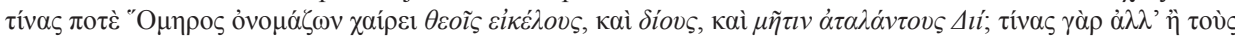

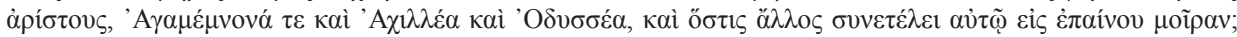
(Max.Tyr., Diss. XXXV 1), “¿Podrías decirme a quiénes gusta Homero de llamar semejantes a los dioses, di- 
Me parece que también los poetas a sus elegidos declaran iguales a los dioses [Il. II 623, 714] divinos, parecidos a los dioses [Il. I 264], comparables en prudencia a Zeus [Il. II 169, 407, 636; X 137], que tienen pensamientos similares a los dioses [Od. XIII 89] y semejantes a los dioses [Il. I 131], royendo el a imagen y semejanza [Gn 1.26]".

Dentro de esta estructura argumentativa, compuesta por la cita 'híbrida' a la obra de Homero, el texto atribuido a Eurípides es otra referencia más que atestigua la perspectiva de Clemente. Indudablemente, desde el contexto inmediato las palabras de Eurípides se relacionan con el tema de la semejanza. En principio, aunque no se emplea el mismo término técnico para referir a la semejanza divina, el texto expone claramente el allegarse a la divinidad como meta última del ser humano. Por consiguiente, la frase Znvì $\pi \rho \circ \sigma \mu i \xi \omega v$ le provee la oportunidad para conectar los versos euripidianos con la secuencia de evidencias escriturales aportadas por los poetas

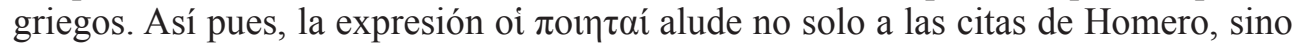
también abarca a Eurípides.

Sin embargo, desde un contexto remoto también las palabras de Eurípides se relacionan con el otro grupo de ideas desarrolladas a lo largo del capítulo con respecto al cuerpo y a la partida celestial. Hay una evidente referencia implícita al

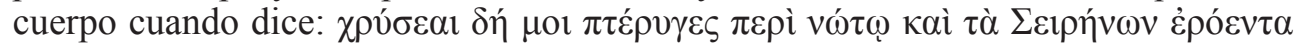
$\pi \varepsilon \dot{\varepsilon} \delta \lambda \alpha \dot{\alpha} \rho \mu o ́ \zeta \varepsilon \tau \alpha 1$. Existe la presencia corpórea, no se niega el valor de cuerpo; por el contrario, el poeta refiere a su espalda ( $v \tilde{\omega} \tau o v)$ y alude a sus pies cuando habla de las sandalias que lleva puestas. Esta postura contrasta notablemente con quienes consideran la morada terrenal como algo despreciable.

Por último, también se puede ubicar dentro de los versos de Eurípides la idea expuesta anteriormente: el ser humano está diseñado para mirar hacia el cielo. Cuan-

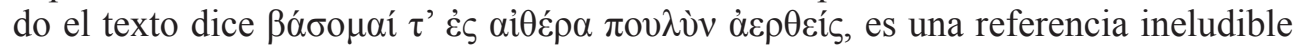
a la partida hacia la morada celestial. La frase "subiré alzándome" da a entender un ascenso, en este caso, hacia el cielo o éter. Esa es la morada final del gnóstico o piadoso; es decir, de aquel que deja la tienda para migrar hacia un destino distinto.

Hasta aquí se ha tratado de situar el texto de Eurípides desde varias dimensiones. Por un lado, ha habido una lectura desde el contexto anterior inmediato; por el otro, también se ha puesto un énfasis especial desde el contexto remoto del capítulo entero. Queda ahora por revisar concretamente la frase donde aparece el término sirenas:

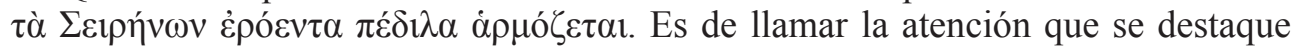
las "sandalias encantadoras" de las sirenas. No resulta evidente la fuente de la cual procede esa información sobre el calzado de esos seres híbridos. Tal vez ese atuendo sea un eco de la antigua literatura épica de los griegos. Suele ser común en Homero la mención a las sandalias, las cuales generalmente llevan un adjetivo para describirlas. Así la expresión $\kappa \alpha \lambda \grave{\alpha} \pi \varepsilon ́ \delta 1 \lambda \alpha$, 'sandalias hermosas', aparece con frecuencia para describir el calzado que llevan puesto los héroes homéricos ${ }^{39}$. Algo similar sucede en

vinos y rivales de Zeus en inteligencia? ¿A qué otros sino a los mejores, a Agamenón, a Aquiles, a Odiseo y a cualquier otro que se contara para él entre los que merecían encomio?" (Campos Daroca). Todos estos epítetos usados para describir el carácter divino de los personajes mencionados son atributos recurrentes en la Ilíada (Campos Daroca 2005: 269). Lo que no es usual es encontrarlos todos juntos en un mismo pasaje para señalar el aspecto divino de ciertos héroes de la antigüedad, por lo que se pudiera pensar que existe un fuente común a estos dos autores donde tales características eran usadas para describir la semejanza con la divinidad, $c f$. Max. Tyr, Diss. XXIII 1.

39 Hom., Il. II 44, X 22 y 132, XIV 186, XXIV 340; Od. I 96, II 4, IV 309, XV 550, XVII 2, XX 126. 
la obra de Hesiodo, donde se habla de 'sandalias áureas' (Hes., Op. 541), o incluso de 'sandalias aladas' (Hes., Sc. 220). Así, la manera en la cual se presenta el calzado de las sirenas en el fragmento euripidiano podría ser una referencia a su carácter divino, pues implícitamente se le pudiera asociar con la forma en la cual hablan los

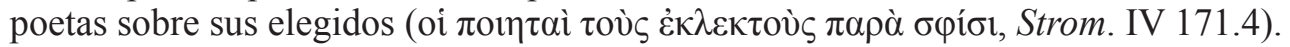

Si las consideraciones anteriores son pertinentes, entonces la adecuación ${ }^{40}$ realizada al texto por Clemente adquiere mayor relevancia ${ }^{41}$. El hecho de que Clemente no conceda la lectura $\pi \tau \varepsilon \rho o ́ \varepsilon v \tau \alpha \pi \varepsilon ́ \delta \imath \lambda \alpha$ puede ser una negación que se resiste a vincular las sirenas con la tradición épica antigua y descarta cualquier rasgo divino

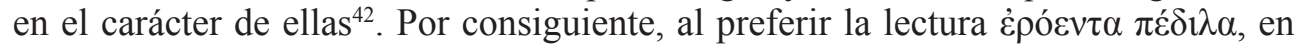
realidad hace una especie de contralectura. Hay un reconocimiento de las supuestas cualidades divinas, pero están encaminadas hacia la voluptuosidad; en todo caso, no serían seres celestiales, sino infernales. Aun con todo, siguen siendo acompañantes funerarios que conducen las almas al más allá y en ese sentido Clemente no se puede sustraer de su contexto cultural.

Sin embargo, a pesar de la modificación al texto, existe al menos un último elemento a considerar en esta revisión. En ocasiones, como ha sido señalado, Clemente introduce adecuaciones a los textos citados, pero esta vez sorprendentemente no sucede así con el término 'sirenas', sino que decide conservarlo. Dicho de otro modo, no le incomoda la presencia de estos seres míticos referenciados en la cita de Eurípides. Sin duda, este hecho es una clara evidencia de la correspondencia simbólica entre el alejandrino y su época. Asume la existencia de las sirenas como parte del imaginario cultural de su entorno, con ello implícitamente se reconoce la importancia de cristianizar los elementos míticos de origen helenístico con la intención de seguir generando espacios de encuentro e hibridación entre el cristianismo y la tradición clásica.

\section{Conclusión}

Clemente de Alejandría es un personaje de frontera, pues habita dos mundos, el cristiano y el clásico. Tal situación de vida le permite situarse en un horizonte cultural híbrido, el cual se puede apreciar a lo largo de su obra. El tema de las sirenas, seres híbridos por excelencia, ofrece una ventana para dilucidar la manera en la cual el alejandrino dialoga con los distintos referentes de su época sin importar el lugar de su procedencia. De esta manera, puede utilizar tanto el texto bíblico como los procedentes de la tradición clásica para referir a las sirenas como núcleo temático de reflexión.

40 La modificación introducida por Clemente tiene como antecedente el juego de palabras (Eros-Pteros) documentado por Platón en el Fedro 252b. En este pasaje se establece una distinción entre los mortales e inmortales para referirse al Amor. Los primeros lo llaman 'Eros', en tanto que los segundos lo denominan Pteros: "Llaman, por cierto, a Eros alado los mortales, los inmortales Pteros, porque fuerza a criar alas” (Gil Fernández 2009: 173).

41 Al respecto Karanasiou (2017) llega a una conclusión similar con respecto a la manera en la cual Clemente recupera los textos de Eurípides. De manera concreta, a modo de conclusión, señala lo siguiente: "His reception of Euripides is not a passive selection that leaves the "borrowed" text unchanged, but is instead an active adaptation: he creates something new by changing the traditional interpretation of Euripides' works" (Karanasiou 2017: 344).

42 De acuerdo con la precisión platónica en Fedro 252b, la designación del 'Amor' con el prefijo $\pi \tau$ correspondería a la designación dada por los inmortales. Al parecer Clemente niega el empleo de esa etimología a las sandalias que portan las sirenas, pues no quiere darle ningún matiz de divinidad a esas criaturas. 
La manera de usar los textos obedece básicamente a su programa teológico en cuestión. No escatima en ningún momento la oportunidad de realizar las adecuaciones pertinentes con el fin de acomodar las citas al desarrollo de su argumento. Desde esta perspectiva se puede afirmar que el alejandrino construye citas híbridas, pues las modificaciones realizadas surgen a partir del diálogo establecido entre el texto y el ambiente cultural dentro del cual se retoma la cita. En este sentido se pudiera señalar la existencia de una nueva realidad 'híbrida' en la que convergen al menos dos horizontes culturales, a saber, el contexto de origen y el de lectura.

No obstante, la noción de hibridismo cultural no se circunscribe solamente a la esfera anterior; por el contrario, hay otros espacios en los cuales también se vislumbran realidades híbridas. El tema mismo de las sirenas marca la pauta para identificar otros escenarios compuestos de realidades culturales múltiples. Hay por lo menos tres indicadores más, en el análisis de los textos revisados, que dan cuenta de un sujeto que vive inmerso dentro de la porosidad de las fronteras culturales. Se evidencia también la posible perspectiva híbrida en el pensamiento de Clemente en: la recuperación de lo 'silvestre' para ampliar la noción de 'pueblo', la construcción y el diseño de citas para acomodar el texto a su perspectiva teológica, la citación conjunta de fuentes de procedencia bíblica y de la tradición clásica.

La manera de proceder del alejandrino es muestra de una situación híbrida donde el intercambio cultural abre la posibilidad de nuevas lecturas de las fuentes utilizadas. Con ello demuestra que ni la identidad ni la cultura cristiana son estáticas o fijas, sino que están en constante modificación y en redefinición permanente. El caso de las sirenas sirve para ilustrar este hecho, pues en la tradición clásica la figura de estos seres fue adquiriendo diferentes matices y el imaginario sobre ellas se fue enriqueciendo de forma paulatina. La recepción de las sirenas en la tradición cristiana no siguió un camino diferente, más bien se perfiló por una senda similar. El trabajo de Clemente ejemplifica claramente dicha situación. Sin duda, retoma motivos e intereses de su época sobre el tema, pero también ofrece lecturas originales como lo expresado en la interpretación del texto isaiano de la Septuaginta donde las sirenas, por su carácter 'silvestre', son un indicio para referir a los no judíos. Esa es una lectura muy particular del alejandrino, en la cual se expone la manera en que el texto adquiere una visión distinta. De igual manera, la lectura del fragmento de Eurípides recupera el tema de las sirenas, pero no se dedica a transcribirlo, sino que lo modifica para reinterpretar a las cantoras funerarias en clave cristiana. Clemente no es un mero reproductor pasivo de textos; por el contario, se encuentra habitando dos espacios, dos mundos culturales y ello le lleva a desarrollar textos e interpretaciones híbridas con el fin de cristianizar la cultura clásica.

Finalmente, el trabajo de Clemente de Alejandría, a pesar de su propio horizonte histórico, es un claro caso de hibridismo cultural. Actualmente la religión sigue siendo parte constitutiva de la identidad cultural de un número importante de personas; por esta razón resulta relevante la obra del alejandrino, porque muestra dos situaciones de manera evidente. Por un lado, es un ejemplo palpable que no hay una especie de 'esencia' cultural que se mantiene perenne detrás de cualquier mutación; lo que hay es un constante intercambio cultural. Por el otro, el diálogo cultural permanente, lejos de socavar la identidad cultural, termina enriqueciendo la visión de la realidad, pues brinda nuevas opciones de lectura. La actitud del alejandrino ofrece un sendero distinto a las alternativas fundamentalistas alojadas en ciertos espacios religiosos contemporáneos. Abrirse a la posibilidad de un intercambio cultural genuino y since- 
ro no es novedoso, sino que es una acción que ya ha tenido una trayectoria importante en la historia del cristianismo, la cual fue iniciada por la recuperación, cristianización e hibridación de los mitos clásicos por parte de los Padres de la Iglesia, entre los cuales destaca Clemente de Alejandría. Lo realmente nuevo y desconcertante es la mirada fundamentalista del cristianismo que supone una cultura originaria al margen del proceso de hibridación de la cultura.

\section{Referencias bibliográficas}

Atienza, A. (2007), «Comedores de pan y bebedores de vino: la cuestión alimentaria en la Odisea», Circe de clásico y modernos 11: 41-56.

Bakker, J.E. (2013), The Meaning of Meat and the Structure of the Odyssey, New York, Cambridge University Press.

Brakke, D. (2010), The Gnostics. Myth, Ritual and Diversity in Early Christianity, Cambridge (Mass.), Harvard University Press.

Burke, P. (2013), Hibridismo cultural, Madrid, Ediciones Akal.

Cantera, F. \& Iglesias, M. (2000), Sagrada Biblia. Versión crítica sobre los textos hebreo, arameo y griego, Madrid, Biblioteca de Autores Cristianos.

Cabrera, P. (2012), «Los seres híbridos. Imágenes de la alteridad en la Grecia Clásica», en A. Bernabé \& J. Pérez de Tudela (eds.), Seres híbridos en la mitología griega, Madrid, Círculo de Bellas Artes: 13-48.

Campos Daroca, F.J., García González, F.J. \& Mariscal Romero, L.P. (2007), «Vida y Vidas de Eurípides» y «Traducción de las Vidas de Eurípides», en F.J. Campos Daroca, F.J. García Gonzalez, J.L. López Cruces \& L.P. Mariscal Romero (ed.), Las personas de Euripides, Amsterdam, Adolf M. Hakkert: 219-252 y 255-291.

Cumont. F. (1989), Astronomía y religión en el mundo grecorromano, Barcelona, Edicomunicación.

Choza, J. \& Choza, P. (1996), Ulises, un arquetipo de la existencia humana, Barcelona, Editorial Ariel.

Descourteeux, M.P. (1999), Les Stromates. Stromate VI, Paris, Les Éditions du Cerf.

$D G E=$ Rodríguez Adrados, F. (dir.) (1995), Diccionario Griego-Español, Volumen II, Madrid, CSIC.

Doherty, L.E. (1995), «Sirens, Muses and Female Narrators in the Odyssey», en B. Cohen (ed.), The Distaff Side. Representing the Female in Homer's Odyssey, New York, Oxford University Press: 81-92.

Fernández Marcos, N. (2000), The Septuagint in Context. Introduction to the Greek Versions of the Bible, Leiden, Brill.

Fernández Marcos, N. (2008), Septuaginta. La Biblia griega de judios y cristianos, Salamanca, Ediciones Sígueme.

Fernández Marcos, N. \& Spottorno Díaz-Caro, Ma V. (2013), La Biblia griega Septuaginta, III. Libros poéticos y sapienciales, Salamanca, Ediciones Sígueme.

Fernández Marcos, N. \& Spottorno Díaz-Caro, Mª V. (2015), La Biblia griega Septuaginta, IV. Libros proféticos, Salamanca, Ediciones Sígueme.

García Gual, C. (2005), Homero: Odisea (Prólogo y traducción), Madrid, Alianza.

García Gual, C. (2014), Sirenas. Seducciones y metamorfosis, Madrid, Turner Noema.

Gil Fernández, L. (2009), Platón: Fedro (Edición bilingüe, introducción y notas), Madrid, Dykinson. 
Hall, S. (2010), Sin garantías: Trayectorias y problemáticas en estudios culturales, Ecuador, Universidad Simón Bolívar.

Hartog, F. (1999), Memoria de Ulises. Relatos sobre la frontera en la antigua Grecia, Argentina, Fondo de Cultura Económica.

Heubeck, A. (1990), A Commentary on Homer's Odissey. Volume II, Books IX-XVI, Oxford, Clarendon Press.

Hofstetter, E, (1990), Sirenen im Archaischen und Klassischen Griechenland, Würzburg, Konrad Triltsch Verlag.

Huerta Rodríguez, J.C. (2020), «Abraham el astrólogo: una lectura intercultural de la obra de Clemente de Alejandría», Collectanea Christiana Orientalia 17: 79-115.

Huerta Rodríguez, J.C. (2018), Exégesis bíblica en Clemente de Alejandría: Uso e interpretación de las citas de los LXX (Pentateuco), Madrid, CSIC.

Jiménez San Cristóbal, A.I. (2012), «Las sirenas», en A. Bernabé \& J. Pérez de Tudela (eds.), Seres híbridos en la mitología griega, Madrid, Círculo de Bellas Artes: 115-151.

Karanasiou, A. (2016), «A Euripidised Clement of Alexandria or a Christianised Euripides? The Interplay of Authority between Quoting Author and Cited Author», en P.E. Cuevas \& J. Martínez J. (eds.), Splendide Mendax: Rethinking Fakes and Forgeries in Classical, Late Antique, and Early Christian Literature, Groningen, Barkhuis: 331-346.

Kelenhegyi, A. (2017), The Beats between Us. The Construction of Identity and Alterity through Animal Symbolism in Late Antique Jewish and Christian Tradition, Budapest, Central European University (Tesis doctoral).

LSJ = Liddell, H.G., Scott, R. \& Jones, H.S. (1996), A Greek-English Lexicon, Oxford, Clarendon Press.

Martínez Bermejo, M. (2017), La recepción de la tragedia fragmentaria de Eurípides. De Platón a Diodoro Sículo, Salamanca, Universidad de Salamanca (Tesis doctoral).

Merino, R. (2003), Clemente de Alejandría. Stromata IV-V, Madrid, Ciudad Nueva.

Merino, R. (2005), Clemente de Alejandría. Stromata VI-VIII, Madrid, Ciudad Nueva.

Momigliano, A. (1975), Alien Wisdom. The Limits of Hellenization, Cambridge, University Press.

Osborne, E. (2005), Clement of Alexandria, Cambridge, University Press.

Pabón, J.M. (1993), Homero. Odisea (Traducción), Madrid, Gredos.

Rahner, H. (2003), Mitos griegos en interpretación cristiana, Barcelona, Herder.

Rankin, D.I. (2006), From Clement to Origen. The social and Historical Context of the Church Fathers, Hampshire, Ashgate Publishing.

Rowley, S. (2014), The Barbarian Sophist. Clement of Alexandria's Stromateis and the Second Sophistic, Oxford, University of Oxford (Tesis doctoral).

Stroumsa, G.G. (2012), «Scripture and Paideia in Late Antiquity», en R.M. Niehoff (ed.), Homer and the Bible in the Eyes of Ancient Interpreters, Leiden, Brill.

Stählin, O. (1906), Clemens Alexandrinus. Zweiter Band Stromata Buch I-VI, Leipzig, J.C. Hinrichs'sche Buchlandlung.

Tapia Zúñiga, P.C. (2017), Homero: Odisea (Prólogo, versión rítmica e índice de nombres propios), Ciudad de México, Universidad Nacional Autónoma de México. 